\title{
A county-level study of the effects of state-mandated COVID-19 lockdowns on urban and rural restaurant visits using consumers' cell phone geo-location data
}

\author{
Tannista Banerjee ${ }^{1}$ (D) $\cdot$ Arnab Nayak $^{2} \cdot$ HaiYue Zhao $^{1}$ \\ Received: 12 August 2020 / Accepted: 28 December 2020 / Published online: 15 January 2021 \\ (C) The Author(s), under exclusive licence to Springer-Verlag GmbH, DE part of Springer Nature 2021
}

\begin{abstract}
Aim US federal, state, and local governments implemented numerous COVID-19 shelter-in-place orders (lockdowns) starting in March 2020 to ensure social distancing regulations and help stop the spread of COVID-19. It is important to know how these lockdowns affected businesses, such as restaurants, in regions that vary in terms of poverty status and geography. In this paper, we analyze the differential changes in rural and urban restaurant visits by the restaurants' NAICS codes following the COVID-19 lockdowns. Our analysis contributes to the public policy literature and helps operational planning for food distribution during a pandemic.

Methods Since urban and rural consumer behavior and food resources are significantly different, it is crucial to conduct a comparative analysis. Our study applies a difference-in-differences model to capture the differential effects lockdowns have on urban and rural restaurants.

Results We find that restaurant visits declined significantly in both rural and urban counties after shelter-at-home orders. The decrease in total restaurant visits was almost twice as high in urban counties as in rural counties. We also find that visits to fastfood restaurants increased in rural counties during shelter-at-home orders.

Conclusions These results contribute to previous studies on the dearth of healthy food in rural and poorer regions, and inform important public policy response in the wake of the COVID-19 pandemic.
\end{abstract}

Keywords Coronavirus $\cdot$ Rural areas $\cdot$ Pandemic $\cdot$ Social distancing $\cdot$ Restaurant

\section{Introduction}

The objective of this research is to estimate the differential changes in rural and urban restaurant visits during COVID19 lockdowns. This study investigates the effect of the COVID-19 lockdowns on visits to different types of restaurant, including fast-food and full-service restaurants, in urban and rural regions. We examine these effects in regard to the income and population differences of the urban vs rural areas.

The spread of the new severe acute respiratory syndrome coronavirus 2 (SARS-CoV-2) has disrupted normal life across

Tannista Banerjee

tzb0018@auburn.edu

1 Department of Economics, Auburn University, 140 Miller Hall, Auburn, AL 36849, USA

2 Department of Economics, Mercer University, Atlanta, Georgia the world. On February 11, 2020, the World Health Organization (WHO) named the disease COVID-19 (World Health Organization 2020). The U.S. Centers for Disease Control and Prevention (CDC) and the WHO announced several health advisories and restrictions on travel and social gatherings. Since then, many countries, including the USA, have issued non-pharmaceutical interventions such as school closures and social gathering bans. State governments ordered statewide shelter-at-home orders, starting with California on March 19, 2020. These executive orders have severely restricted the social life of the US population. Though this is an important step in containing the spread of the deadly virus, these shelter-at-home orders significantly impacted businesses, including restaurants.

The restaurant and food service industry, including fastfood counter workers, was the largest employmentgenerating sector in the U.S in 2019 (United States Bureau of Labor Statistics 2020). Restaurants, including full-service and fast-food locations, play many roles in the US economy 
because of their different characteristics. According to the National Restaurant Association, the US population spends more on food and drink outside the home than on food at home (National Restaurant Association 2019). Food and beverage service businesses observed a $4.4 \%$ increase in sales in 2019 compared to 2018. However, from February to March 2020, food and beverage service businesses observed an $8.7 \%$ drop in sales, which was also $6.2 \%$ below March 2019 sales (United States Census Bureau 2020). Given the large number of people employed in this sector in the USA, the COVID-19 lockdowns have had a catastrophic effect on the industry and, in turn, on US employment. In this paper, we analyze the differences in COVID-19 effects across rural and urban restaurants.

There is some recent literature that focuses on the impact of the COVID-19 lockdown on food preferences. Laguna et al. (2020) studied consumers' food selections in relation to the COVID-19 crisis and showed that during the pandemic, consumers reduced the frequency of shopping. There is some correlation with product purchase and mood enhancement. Grashuis et al. (2020) supported the above result by showing that the COVID-19 crisis negatively affected grocery shopping frequency in highly affected areas. It also encouraged more online grocery shopping (Robertson 2020; Butu et al. 2020). The COVID-19 pandemic encouraged consumers to stock up on food (Wang et al. 2020) so they could reduce their shopping frequency. There is also a growing branch of research focusing on the differences in food access between urban and rural counties (Block 2006; James et al. 2014; Sharkey 2009). Rural and urban residents have different preferences for and access to food (Weinberg 2000). From these studies, we can expect that COVID-19 lockdowns had differential effects on food priorities of urban and rural consumers. The change in food access behavior is also expected to change restaurant visit behavior.

Some scholars have studied the effect of COVID-19 lockdowns on the restaurant industry. Kim and Lee (2020) showed that risk-averse consumers will prefer more private dining; more than half of all restaurants will not survive as a result of the COVID-19 pandemic (Severson and Yaffe-Bellany 2020). Cranfield (2020) is the first researcher to raise the issue that household income, time, and allocation of resources will lead to substitution behaviors within and between food groups - and in restaurant visits - during the COVID-19 lockdowns. As people change their work and stay-at-home behavior, it will affect both urban and rural consumers' restaurant purchases. However, to the best of our knowledge, there has not been any econometrics study with detailed microlevel data analyzing the effects of COVID-19 lockdowns on the restaurant sector. This article aims to fill these gaps by analyzing the differential changes in rural and urban restaurant visits following COVID-19 lockdowns.
The paper uses geolocation data from millions of mobile users across the USA. We compare restaurant visits before and during the lockdowns. We also compare these effects across the different categories of restaurants, as characterized by the restaurants' NAICS codes. This helps us address the effect of COVID-19 and statewide shelter-at-home orders on different kinds of rural and urban restaurant visits. The article is organized as follows: we next describe the theoretical prediction and research question, then we introduce our data and methodology, and finally, we share our analysis and results. The final section is the conclusion.

\section{Theoretical facts from the literature}

Multiple factors impact restaurant visits. Below we outline those in the literature that are most related to our study.

\section{Urban-rural food access differences}

Regional differences - that is, conditions in urban versus rural areas in term of food environment - can influence food consumption. Burgoine and Harrison (2013) concluded that there are more food outlets and a wider variety of foods available in urban than in rural regions. These food outlet differences could impact consumers' food decisions significantly. For example, Dean and Sharkey (2011) found that the differences between urban and rural retail food environments cause rural residents to consume less fruits and vegetables than urban residents. It is also shown that urban residents have a higher incidence of eating food away from home than do rural residents (Zeng and Zeng 2018). These food consumption differences lead to different resident health statuses. Anderson et al. (2015) found that persons living in rural US counties are more likely to have poorer health outcomes than those living in urban areas. These results are due to the limited availability of affordable, nutritious food in rural areas. This highlights the importance of investigating the effect of COVID-19 lockdowns differentially for urban and rural regions; and we must examine restaurant visits, which have also been explored in the literature.

\section{Urban and rural income differences}

Food is a normal good, so income is a relevant explanatory variable for our analysis. One of many interesting research questions is how people make their food decisions based on their financial status. For example, previous research has found that in the Supplemental Nutrition Assistance Program (SNAP), participants have higher consumption shortly after receiving their benefits, followed by lower consumption toward the end of the benefit month. Smith et al. (2016) studied the SNAP benefit cycle and showed that short- 
run impatience and fungibility of income could be the main things influencing short-run consumption fluctuations. However, consumers who are more willing to buy organic food products are positively influenced by their income and nutrition knowledge (Gracia and de Magistris 2008). There is also research in China proving that increased income could affect diets and body composition in a manner detrimental to one's health, with those in low-income groups having the largest increase in detrimental effects due to increased income (Du et al. 2004). Researchers have also studied how income affects food purchase and waste behavior. When considering food typologies that include high value-added products, mid-to-low income consumers purchase higher amounts of lower quality products and waste more food (Setti et al. 2016). Such findings give support to the hypothesis that low-income individuals are more likely to consume lower quality foods and are more impatient about their food decisions. This literature supports including income as a control variable in our analysis.

\section{Population under the poverty level}

Since more people under the poverty level probably indicates a lower median household income, it is expected that these two variables have an opposite effect on restaurant visits.

\section{Population}

Persons who live in higher populated areas are more likely to have frequent restaurant visits than those who live in less populated areas. A larger population means greater demand. Population is an important variable in determining the restaurant foot traffic in our analysis and, therefore, we include the population of the region as an important control variable.

\section{Urban and rural COVID-19 cases and deaths}

The literature [Grashuis et al. (2020); Kim and Lee (2020)] has shown that increases in COVID-19 cases and deaths influence consumers' food access decisions. Consumers changed their food purchase decisions depending on COVID-19 infection and mortality rate increases in their regions. Figure 1 (below) shows that restaurant visits decline with COVID-19 case increases. Therefore, COVID-19 cases and deaths are important variables to consider in our analysis. We obtained data on coronavirus cases and deaths by county from the CDC's coronavirus databases and Johns Hopkins University's COVID-19 dashboard, and we cross-checked this with the New York Times coronavirus cases dashboard (The New York Times 2020; Centers for Disease Control and Prevention 2020; Johns Hopkins University 2020). ${ }^{1} \mathrm{We}$

\footnotetext{
${ }^{1}$ If there are no reported coronavirus cases or deaths for a day, we assume the number is zero.
}

matched the weekly restaurant visits database with the shelter-in-place orders and coronavirus cases by the 12-digit FIPS code for the county (Silberholz 2020).

\section{Treatment variable}

Shelter-in-place orders ask residents to stay at home, except for work, local essential shopping, and other permitted errands. These orders impacted restaurants significantly since they lost most of their dine-in patrons. We obtained statelevel shelter-in-place orders from the New York Times 2020 data page titled: See Which States and Cities Have Told Residents to Stay at Home. The shelter-in-place orders include state and local government-imposed social distancing regulations implemented, or in place, from February 1, 2020 to April 5,2020 . This is the main treatment variable in our analysis, as we want to study how these orders relate to the food access literature mention above and analyze the effect of COVID-19 lockdowns between urban and rural regions.

\section{Data and methodology}

We linked several databases together for the analysis. The first database used is the central restaurant visitor data in the USA. The database is obtained from SafeGraph's 'Core Places' database (SafeGraph (2020)). ${ }^{2}$ SafeGraph tracks consumers' mobile devices with their consent (using different sources) and tracks daily visits to hundreds of thousands of points of interest in the USA, including all kinds of restaurants. SafeGraph uses GPS pings from different mobile applications to estimate foot traffic patterns in restaurants in the USA. This detailed database provides daily consumer visit data to different restaurants by address, zip code, and 12-digit block-group FIPS codes. Using this data, we aggregated daily visits to get weekly visits for each restaurant within a 12-digit FIPS code area. We dropped duplicate observations by restaurants within a day (this was less that $0.03 \%$ ). Our data is restaurant level, and each restaurant is one observation within a day. We calculated total weekly restaurant visits per 1000 population (i.e., all our restaurant visit rates are calculated per 1000 of population of the corresponding counties. This SafeGraph data also includes all curbside pickups by food delivery services. However, since workers are excluded from the visit counts, if restaurant workers did home deliveries, that would be excluded from the database.

SafeGraph acknowledges small geographical biases in the data collection due to tower tracking technological

\footnotetext{
${ }^{2}$ SafeGraph, a data company aggregates anonymized location data from numerous applications in order to provide insights about physical places, via the Placekey Community. To enhance privacy, Safegraph excludes census block group information if fewer than five devices visited an establishment in a month from a given census block group.
} 
differences. However, SafeGraph measured these small geographical biases in the data and found the range of these biases to be from less than $1 \%$ to a maximum of $3 \%$ in any state.

The period of the database used in this study is from February 1, 2020 to April 5, 2020 for all counties in the USA. We selected this period to analyze changes in restaurant visits immediately before and during the COVID-19 pandemic in the USA. For this analysis, we concentrate on four different kinds of restaurants defined by the NAICS codes: (1) full-service restaurants, (2) fast-food and quick-service restaurants, including McDonald's, Burger King, etc., (3) buffet restaurants, and (4) nonalcoholic drink bars such as Starbucks.

We added county-level income and poverty data from the U.S. Census Bureau and Small Area Income and Poverty Estimates (United States Census Bureau 2019) respectively. By merging the latter data with the block-group FIPS code for the restaurants, we added economic control variables in our model. Next, we obtained the rural-urban characteristics of counties from the United States Department of Agriculture Economic Research Service's (2020) Rural-Urban Continuum Codes. If the code is higher than 3 , the county is categorized as rural (following federal rules).

\section{Independent variables}

The independent variables were as follows: county cases (total number of cases), county deaths (total number), median income (in thousands of dollars), population below poverty level (in percentage), urban and rural differences ( 1 if respondent lived in an urban or suburban area; 0 otherwise), population (total population), and restaurant category ( 1 if restaurant matches the category full-service, fast food, buffet, or drink bar; 0 otherwise).

Table 1 presents the summary statistics for all variables. It shows that the average per week visits to any restaurant open in the urban counties is 56 for the weeks from February 1 to April 5, 2020. The corresponding average weekly visits for all open rural restaurants is 49 during the same period. For the time considered in this paper, average urban COVID-19 cases are 122, and rural cases are 1.4. Urban death rates are also higher than in the rural areas. Urban median household income is, on average, $\$ 68,395$, while the average rural income is $\$ 50,365$. About $13 \%$ of urban county residents are below the poverty level, whereas about $15 \%$ of rural county residents are below the poverty level. The $p$ values representing the significance of the differences between the means are listed at the bottom of the table. The $p$ values range from 0.001 to 0.003 , and show that there are significant differences between urban and rural restaurant visits, the extent of COVID-19 spread, and resident incomes.

We present the change in the total US weekly restaurant visits per 1000 population (the red line) in Fig. 1. The $x$-axis represents the days from February 1 to April 5. The $y$-axis is the total number of COVID-19 cases (i.e., the actual count) in the USA (blue line; left $y$-axis) and restaurant visits per 1000 population (right $y$-axis). According to Fig. 1, per capita weekly US restaurant visits started to decrease around the end of February. This was when media outlets started reporting the COVID-19 pandemic spread within small communities in the USA and people became more apprehensive. After COVID19 cases increased in the USA (i.e., after March 1), there were rapid drops in restaurant visits until April 5. Figure 1 shows a clear negative connection between per capita restaurant visits and the number of COVID-19 cases.

\section{Estimation strategy}

We indicate the treatment variable as a dummy taking the value 1 for the dates the shelter-in-place order was implemented in the county, from February 1 to April 5, 2020. Urbanit and rural $_{i t}$ are binary variables representing the urban and rural status of county $i$. The control groups for the urban and rural counties are the urban and rural counties with no effective shelter-in-place orders. We estimate the difference-in-
Table 1 Summary statistics for all variables

\begin{tabular}{llllll}
\hline & Weekly visits & $\begin{array}{l}\text { County } \\
\text { cases }\end{array}$ & $\begin{array}{l}\text { County } \\
\text { deaths }\end{array}$ & $\begin{array}{l}\text { Median } \\
\text { Income }\end{array}$ & $\begin{array}{l}\text { Population below } \\
\text { poverty level }\end{array}$ \\
\hline Urban counties & 56.048 & 121.527 & 2.067 & $68,394.99$ & 12.723 \\
& $(105.76)$ & $(561.47)$ & $(10.13)$ & $(17,793.45)$ & $(4.38)$ \\
Rural counties & 48.581 & 1.377 & 0.017 & $50,364.6$ & 15.496 \\
Total U.S. & $(81.84)$ & $(8.05)$ & $(0.16)$ & $(10,089.62)$ & $(5.52)$ \\
& 55.11 & 106.432 & 1.809 & $66,129.82$ & 13.071 \\
$P$-value & $(103.09)$ & $(526.53)$ & $(9.50)$ & $(18,036.95)$ & $(4.64)$ \\
\hline
\end{tabular}

This table presents the means and standard deviations (presented in parentheses below the mean).

All county-level weekly restaurant visits are per 1,000 population of the counties. All COVID cases and deaths are actual numbers. 


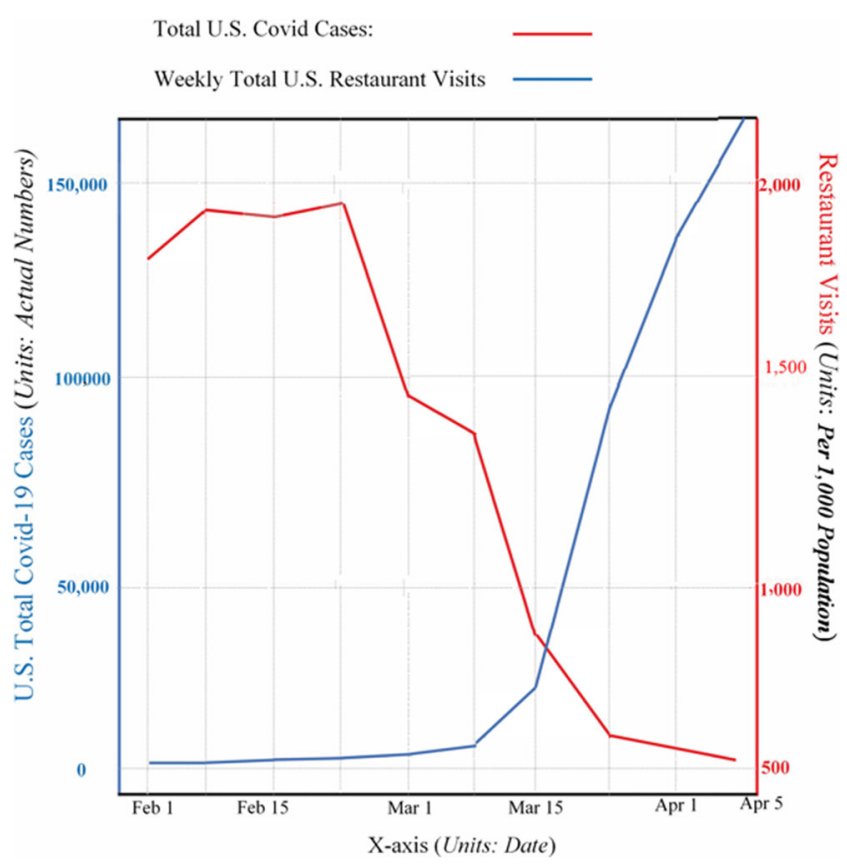

Fig. 1 Total US Covid 19 cases (blue) and total US restaurant visits per 1000 of population $(\mathrm{red})$

differences specification (DID) - i.e., the comparative changes in restaurant visits across urban and rural counties, and between those counties that had effective lockdowns versus those counties that did not - as:

$$
\begin{aligned}
\ln \left(\text { visit }_{j i t}=\right. & \beta_{1}\left(\text { urban }_{i t} \times \text { treatment }_{i t}\right) \\
& +\beta_{2}\left(\text { rural }_{i t} \times \text { treatment }_{i t}\right)+\alpha X_{i t-1}+t \\
& +\varepsilon_{i j t .}
\end{aligned}
$$

In the above Eq. (1), the dependent variable is the natural logarithm of weekly visits to restaurant $j$ in county $i$ for week $t$. $\ln (v i s i t)_{j i t}$ represents natural logarithm. The $u_{r b a n}$ and rural $_{i t}$ variables represent the urban or rural status for restaurant $j$ 's county for week $t$. The slope coefficients $\beta_{1}$ and $\beta_{2}$ estimate average responses to state-mandated orders between the treatment and control counties.

The coronavirus spread could differentially influence the following week's restaurant visits. To capture this effect, we include the county-level previous week's coronavirus deaths in our first specification, as this captures the pandemic nature of the disease and public health hazard. $X_{\mathrm{it}-1}$ represents lagged weekly county-specific variables and include county-specific coronavirus deaths during the week $(t-1)$. The slope coefficient $\alpha$ estimates the lagged county-specific effects on weekly restaurant visits.

We also include contemporaneous and previous week coronavirus cases as well as state-specific cases as robustness checks in separate specifications. Median household income, percentage of people under the poverty level, and population are added as additional controls for the county. Time-fixed effects are included. The fixed effect controls for the time variation in the data. These variations include coronavirus testing rates, political partisan differences occurring on a daily basis, etc. Standard errors are clustered at the state level.

\section{Results}

This section discusses the results of the paper.

Estimation results for Eq. (1) for all kinds of restaurants are presented in Table 2. The first column of Table 2 shows that the shelter-in-place orders decreased weekly urban restaurant visits by $16 \%$ and weekly rural restaurant visits by $8 \%(p$ value 0.001 and 0.000 ). These effects are significant at the $1 \%$ level (99\% level of confidence) for both urban and rural counties. We conducted an F-test, which rejects the equality between urban and rural coefficients at $99.9 \%$ confidence. Therefore, the effect of the shelter-in-place orders is higher for urban restaurant visits than for rural restaurant visits. This shows that urban restaurants faced almost double the negative effect of COVID-19 pandemic than rural restaurants.

The most interesting result in Table 2 is that in counties with higher proportions of their population under the poverty level, restaurant visits are $23 \%$ higher ( $p$ value 0.001 ). This effect is verified by the second column of Table 2, which shows that as median income is higher in a county, restaurant visits are lower. Since having more people under the poverty

Table 2 All restaurant visits

\begin{tabular}{lll}
\hline Dependent variable: & 1 & 2 \\
& $\ln$ (visits) & ln (visits) \\
\hline Urban x treatment & $-0.159^{* * *}$ & $-0.156^{* * *}$ \\
& $(0.001)$ & $(0.001)$ \\
Rural x treatment & $-0.075^{* * *}$ & $-0.079^{* * *}$ \\
& $(0.003)$ & $(0.003)$ \\
County deaths & $-0.005^{* * *}$ & $-0.005^{* * *}$ \\
& $(0.000)$ & $(0.000)$ \\
Percentage of households under & $0.230^{* * *}$ & \\
poverty level & $(0.001)$ & \\
Median household income & & $-0.465^{* * *}$ \\
& & $(0.000)$ \\
Population & 0.001 & $0.001 * * *$ \\
& $(0.000)$ & $(0.000)$ \\
Time-fixed effect & Yes & Yes \\
Constant & $3.896^{* * *}$ & $4.146 * * *$ \\
& $(0.012)$ & $(0.006)$ \\
Observation & $2,793,367$ & $2,793,367$ \\
\hline
\end{tabular}

The dependent variable is the log of weekly visits to the restaurant. $\ln$ (visit) represents natural logarithm.

Standard errors are in parentheses.

$* * * p<0.01$ 
Urban Restaurant Visits

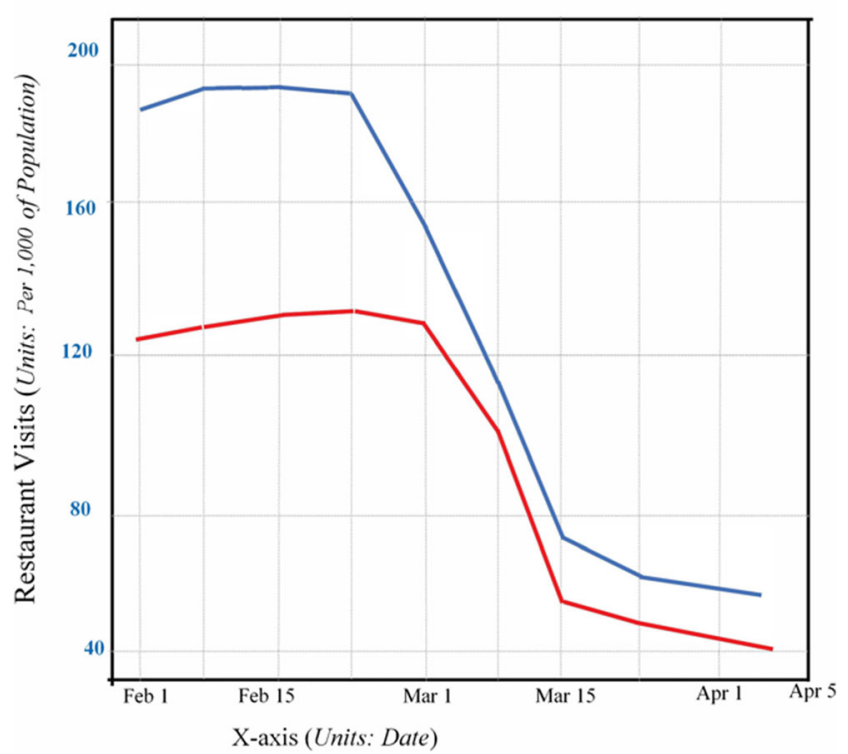

Fig. 2 All restaurant visits per 1000 population across urban and rural counties

level probably also indicates a lower median household income, it is expected that these two variables have opposite effects on restaurant visits. These last two results show that the shelter-in-place orders caused bigger drops in restaurant visits in wealthier counties than in less wealthy counties. We also check the robustness of the results with additional controls for county COVID-19 cases and state COVID-19 cases/ deaths, with no significant change in the conclusion.

Figure 2 demonstrates the rural and urban weekly total number of visits (per 1000 of population) aggregated across all restaurant types. We see that when we represent all four types of restaurants together, both urban and rural visitor counts have fallen sharply after March 15. Figure 2 further illustrates a greater negative effect of the COVID-19 pandemic on urban restaurants compared to rural restaurants.

Next, we estimate the average effects of the shelter-in-place orders for urban and rural counties by different restaurant types, as categorized by their NAICS codes. Results are presented in Table 3. Column 1 shows that for urban and rural counties, shelter-in-place orders decreased the weekly visits to full-service restaurants by $19 \%$ and $13 \%$ ( $p$ value 0.001 and 0.000 ) respectively. Post-estimation test of equality between the urban and rural coefficients ( $p$ value 0.0027 ) confirms that the two coefficients are significantly different. Therefore, COVID-19 and the shelter-in-place orders had a greater negative effect for urban restaurant visits than for rural restaurant visits, after controlling for economic factors and the severity of the pandemic. All the health and economic variables in Table 3 have similar effects to those seen in Table $2 .^{3}$ For

\footnotetext{
${ }^{3}$ COVID-19 death values are lagged one week to control for possible endogeneities.
}

example, previous-week deaths has a negative effects on all restaurant visits. Percentage of households under the poverty level has a positive effect on every type of restaurant, which means restaurant visits increase as the county is less wealthy.

Column 2 of Table 3 shows that after the shelter-in-place orders were issued, weekly visits to fast-food restaurants significantly decreased by $4 \%$ for urban counties. However, for rural counties the shelter-in-place orders increased fast-food restaurant visits by $10 \%$. The effect is significant at the $99 \%$ level of confidence ( $p$ value 0.001 ). In addition, Table 3 shows that counties with more people under the poverty level had $23 \%$ more fast-food restaurant visits. This is the largest effect among all restaurant types.

Column 3 of Table 3 shows that for both rural and urban counties, buffet restaurants were more highly and significantly affected. Their weekly visits decreased by $47 \%$ and $95 \%$ ( $p$ values 0.000 and 0.000 ), respectively. This indicates that it will most probably be difficult for these businesses to survive the COVID-19 lockdowns. This makes sense, as it may be difficult to maintain social distancing in buffet restaurants, given the nature of their services. Column 4 of Table 3 shows that drink bars such as Starbucks are have also been affected by shelter-in-place orders. The negative effect on drink bars is significant for both urban and rural counties $(17 \%$ and $8 \%$ fewer visits respectively). A post-estimation test for equality between urban and rural coefficients shows significant differences at the $92 \%$ level. We use the percentage of people under the poverty level to control for economic status in Table 3.

Separately, we have also considered median household incomes instead of the percentage of people under the poverty level, as used in Table 3. These results are presented in Table 4. Here, too, we find that median household income has a negative effect on different restaurant visits; however, the effect is not significant for buffet restaurants. This shows that as the COVID-19 pandemic started in the USA, people with higher per capita incomes could afford to stay inside and eat more at home than people with less income.

\section{Relating results to the theoretical and practical findings in the literature}

The results above depict the substitution effect of rural counties toward more fast-food restaurants after the lockdowns (Ko et al. 2018). Since many full-service restaurants in rural areas are family owned, they were slower to adopt new regulations (Ko et al. 2018; Center for Science in the Public Interest 2014). Because $15.5 \%$ of rural residents live in foodinsecure households (Ko et al. 2018; Binkley 2006), they mainly frequent fast-food restaurants with cheaper prices (Ko et al. 2018), even under the pandemic situation.

The substitution effect of rural counties toward fast-food restaurants after the COVID-19 lockdowns is further illustrated in Fig. 3. The $x$-axis represents the days from February 1 to 
Table 3 Regression results by restaurant type

\begin{tabular}{|c|c|c|c|c|}
\hline & $\begin{array}{l}1 \\
\text { Full service }\end{array}$ & $\begin{array}{l}2 \\
\text { Quick service/fast food }\end{array}$ & $\begin{array}{l}3 \\
\text { Buffets }\end{array}$ & $\begin{array}{l}4 \\
\text { Drink bars }\end{array}$ \\
\hline Urban $\mathrm{x}$ treatment & $\begin{array}{l}-0.192 * * * \\
(0.001)\end{array}$ & $\begin{array}{l}-0.043 * * * \\
(0.002)\end{array}$ & $\begin{array}{l}-0.471 * * * \\
(0.089)\end{array}$ & $\begin{array}{l}-0.176^{* * * *} \\
(0.003)\end{array}$ \\
\hline Rural $\mathrm{x}$ treatment & $\begin{array}{l}-0.134 * * * \\
(0.004)\end{array}$ & $\begin{array}{l}0.107 * * * \\
(0.006)\end{array}$ & $\begin{array}{l}-0.952 * * * \\
(0.278)\end{array}$ & $\begin{array}{l}-0.080 * * * \\
(0.008)\end{array}$ \\
\hline County deaths & $\begin{array}{l}-0.003 * * \\
(0.001)\end{array}$ & $\begin{array}{l}-0.001 * * * \\
(0.001)\end{array}$ & $\begin{array}{l}-0.004 \\
(0.003)\end{array}$ & $\begin{array}{l}-0.004 * * * \\
(0.000)\end{array}$ \\
\hline Percentage of household under poverty level & $\begin{array}{l}0.204 * * * \\
(0.001)\end{array}$ & $\begin{array}{l}0.226 * * * \\
(0.001)\end{array}$ & $\begin{array}{l}0.184 \\
(0.335)\end{array}$ & $\begin{array}{l}0.089 * * \\
(0.001)\end{array}$ \\
\hline Population & $\begin{array}{l}0.032 * * * \\
(0.001)\end{array}$ & $\begin{array}{l}0.005 * * * \\
(0.001)\end{array}$ & $\begin{array}{l}0.048 \\
(0.269)\end{array}$ & $\begin{array}{l}0.034 * * * \\
(0.001)\end{array}$ \\
\hline Time fixed effect & Yes & Yes & Yes & Yes \\
\hline Cons & $\begin{array}{l}3.935 * * * \\
(0.007)\end{array}$ & $\begin{array}{l}4.669 * * * \\
(0.012)\end{array}$ & $\begin{array}{l}2.666 * * * \\
(0.001)\end{array}$ & $\begin{array}{l}3.007 * * * \\
(0.015)\end{array}$ \\
\hline Observation & 1738.307 & 593,436 & 1811 & 460,883 \\
\hline
\end{tabular}

Dependent variable is the natural log of weekly visits to the restaurant.

Standard errors are in parentheses.

$* * * p<0.01, * * p<0.05$

April 5, and the $y$-axis is fast-food restaurant visits per 1000 population by urban and rural areas. Figure 3 shows COVID19 lockdowns have a differential effect across urban and rural counties. Per capita weekly US fast-food restaurant visits started to decrease around the end of February, but around
March 5 (when all the COVID-19 lockdowns started), the decline in urban fast-food restaurant visits exceeded the decline in rural fast-food visits. Figure 3 also shows that around March 15, fast-food restaurant visits started to increase in rural areas, whereas fast-food restaurant
Table 4 Regression results by restaurant types

\begin{tabular}{lllll}
\hline & 1 & 2 & 3 & 4 \\
& Full service & Quick service/fast food & Buffet & Drink bars \\
\hline Urban x treatment & $-0.190^{* * * *}$ & $-0.041^{* * *}$ & $-0.470^{* * *}$ & $-0.174^{* * *}$ \\
& $(0.001)$ & $(0.002)$ & $(0.089)$ & $(0.003)$ \\
Rural x treatment & $-0.138^{* * *}$ & $0.103^{* * *}$ & $-0.929 * * *$ & $-0.084 * * *$ \\
& $(0.004)$ & $(0.006)$ & $(0.006)$ & $(0.001)$ \\
County deaths & $-0.003^{* * *}$ & $-0.003^{* * *}$ & -0.004 & $-0.004 * * *$ \\
& $(0.000)$ & $(0.000)$ & $(0.153)$ & $(0.001)$ \\
Median household income & $-0.384^{* * *}$ & $-0.487 * * *$ & -0.063 & $-0.256^{* * *}$ \\
& $(0.001)$ & $(0.001)$ & $(0.836)$ & $(0.001)$ \\
Population & $0.053^{* * *}$ & $0.028^{* * *}$ & 0.054 & $0.047 * * *$ \\
Time fixed effect & $(0.001)$ & $(0.001)$ & $(0.221)$ & $(0.001)$ \\
Cons & Yes & Yes & Yes & Yes \\
& $7.141^{* * *}$ & $0.129 * * *$ & 3.749 & $5.907 * * *$ \\
Observation & $(0.005)$ & $(0.010)$ & $(0.254)$ & $(0.012)$ \\
\hline
\end{tabular}

Instead of using percentage of people under the poverty level as done in Table 3, we use median household income here.

The dependent variable is the log of weekly visits to the restaurant. The dependent variable is the natural $\log$.

Standard errors are in parentheses.

$* * * p<0.01$ 
Fig. 3 Fast-food restaurant visits per 1000 population across urban and rural counties

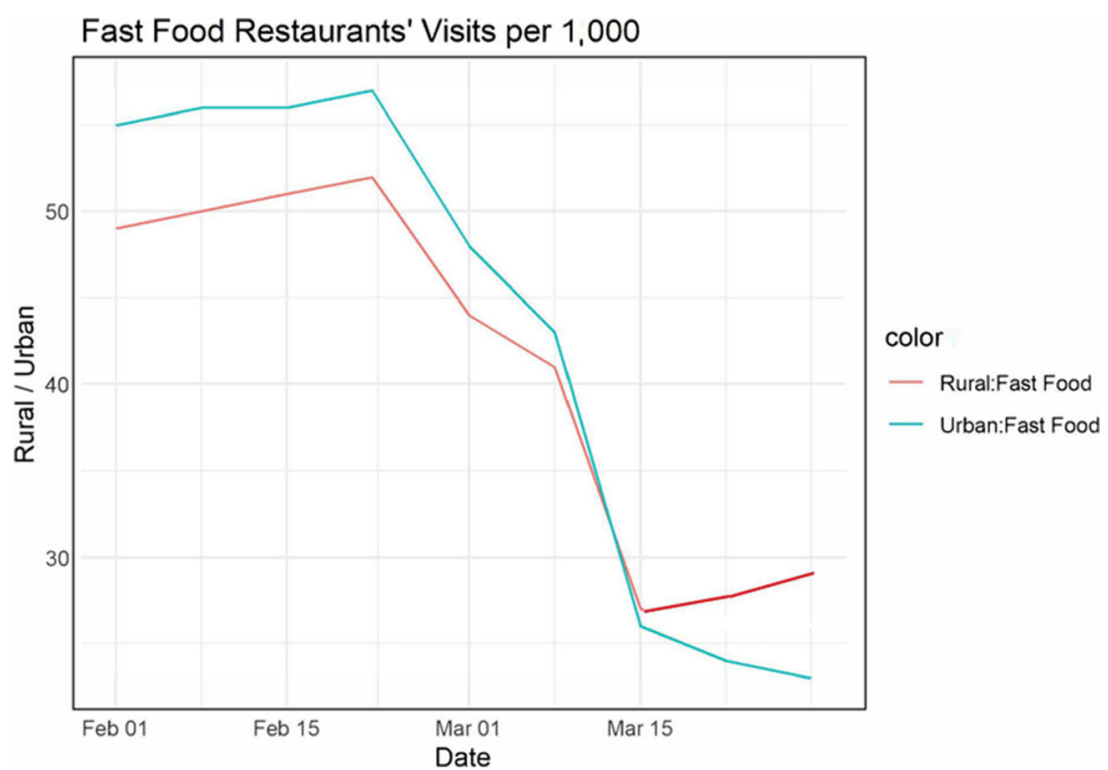

visits continued to decrease in urban areas. This shows the substitution effect of rural counties toward fast-food restaurants after the COVID-19 lockdowns. It also shows that targeted policies are needed for both urban and rural counties to improve healthy food consumption during pandemics.

\section{Discussion}

In recent years, our understanding of urban and rural differences (such as income, education, physical health status, food environment, etc.) has got better, and this has become even more important during the COVID-19 pandemic. Shelter-inplace orders have proved to contain the spread of the virus, but the lockdown policies have impacted the economy. We need targeted public policies to help the economy recover and help various industries, including the highly affected food sector and restaurant industry. It is important to understand the differential effects of COVID-19 lockdowns on urban vs rural restaurants for planning and policy purposes. Our study helps in this area, as it is the first with detailed microlevel data analyzing the lockdown effects on urban and rural restaurants. Thus, it not only forms a basis for future research directions, but also provides data for urban and rural comparisons.

One interesting question is why fast-food restaurant visits showed opposite trends in urban regions to those in rural regions after the COVID-19 lockdowns. Kim and Leigh (2011) showed that fast-food restaurants were "normal goods" for below-average income families, but "inferior goods" for above-average income families. Full-service restaurants were "normal" for virtually all income levels. The results of this paper highlight these phenomena, as we found that there were increased visits to fast-food restaurants in rural areas under the lockdowns. After the shelter-in-place orders, we observed an increase in unemployment and a significant decrease in income. Most rural residents already have lower incomes; but with even less income and the reduction in options that came with the lockdowns, fast-food restaurants became more desirable. Therefore, the substitution effect of rural counties toward fast-food restaurants after the COVID-19 lockdowns shows that rural areas became more dependent on unhealthy food options after the COVID-19 lockdowns.

A second interesting effect we observed is that overall urban restaurants faced almost double the negative effect of the COVID-19 pandemic to that for rural restaurants. Zeng and Zeng (2018) illustrated that urban residents had a higher rate of food away from home than rural residents before the pandemic. When shelter-in-place orders were imposed, both urban and rural areas were affected abruptly, and it is reasonable to observe a larger relative decrease in urban restaurant visits than in rural restaurants.

Many restaurants moved to curbside pickups or deliveries during the pandemic period. Since we are using weekly restaurant visit data, our results capture the curbside pickups by individual customers and food delivery services such as Grubhub, Uber Eats, etc. Therefore, our results give an ideal estimate of the pandemic's effect on rural and urban counties' restaurants.

At the county level, it is possible to see some variation in implementation of shelter-in-place orders. Some rural counties instituted policies later than urban ones. Some rural counties might get more time for voluntary behavioral changes than urban counties. Since we considered statewide shelterin-place orders and also compared urban and rural counties, our results show true variation in the shelter-in-place orders. 
The study has some limitations. While we collect a wide range of microlevel data on restaurant visits, we do not include the number of local supermarkets in our model. However, we do control for this using income and poverty-level data. One of many other possible future research directions could be considering local communities' demographics such as gender, age, race, etc. Since different communities have different resident characteristics, it is reasonable to assume that they may have different responses to the pandemic and shelter-at-home orders, and it would be interesting to further dissect the visit data by these characteristics. Though outside the scope of our study, it would be interesting to study the other policies shutting down businesses and public places and restricting gathering sizes. These policies could also affect restaurant visits. Despite these and other possible limitations, this paper plays an important role in exposing how the COVID-19 pandemic affected rural and urban restaurant visits differently.

\section{Conclusion}

Our findings have several policy implications. Fast-food substitution is known to be detrimental to community-wide health outcomes, and the reliance of rural counties on fast food under duress might reflect deeper concerns as to the types of food availability and choices. Effective targeted public health policy is needed to improve the health status of rural communities during pandemics.

In terms of operational planning, our results show that fastfood restaurant owners in rural areas may want to consider investing in labor resources to expand capacity, at least temporarily, to handle the increased demand. Policymakers should be aware of these changes to prevent gathering and waiting time in rural fast-food restaurants. There could be some change in rural and urban restaurant competitiveness as a result of the pandemic. In addition, urban restaurants faced almost double the negative effect of the COVID-19 pandemic compared to rural restaurants. Policymakers need to help urban restaurants survive the pandemic.

Acknowledgments We thank SafeGraph for making the data available.

Authorship contribution Dr. Banerjee procured the Safegraph Database. All authors contributed personally and actively in the data analysis and wrote the paper. All authors are jointly and personally responsible for the content of the paper.

Data availability Database is available here: https://ocs.safegraph.com/ docs/social-distancing-metrics

\section{Compliance with ethical standards}

Conflict of interest The authors have no conflict of interest
Ethics approval Not applicable.

Consent to participate Not applicable.

Consent for publication Not applicable.

Code availability Software STATA has been used. Code is available from authors upon request.

\section{References}

Anderson TJ, Saman DM, Lipsky MS, Lutfiyya MN (2015) A crosssectional study on health differences between rural and non-rural U.S. counties using the county health rankings. BMC Health Serv Res 15:441-448. https://doi.org/10.1186/s12913-015-1053-3

Binkley JK (2006) The effect of demographic, economic and nutrition factors on the frequency of food away from home. J Consumer Affairs 40(2):372-391. https://doi.org/10.1111/j.1745-6606.2006. 00062.x

Block D (2006) What fills the gaps in food deserts? Mapping independent groceries, food stamp card utilization and chain fast-food restaurants in the Chicago area. Appetite 47(3):386. https://doi.org/10.1016/j. appet.2006.08.012

Burgoine T, Harrison F (2013) Comparing the accuracy of two secondary food environment data sources in the UK across socio-economic and urban/rural divides. Int J Health Geogr 12:1-8. https://doi.org/10. 1186/1476-072X-12-2

Butu A, Brumă IS, Tanasă L, Rodino S, Vasiliu CD, Doboș S, Butu M (2020) The impact of COVID-19 crisis upon the consumer buying behavior of fresh vegetables directly from local producers. Case study: the quarantined area of Suceava County, Romania. Int $\mathbf{J}$ Environ Res Public Health 17(15):5485. https://doi.org/10.3390/ ijerph17155485

Center for Science in the Public Interest (2014) State and menu labeling policies. https://cspinet.org/new/pdf/ml_map.pdf. Accessed April 2020

Centers for Disease Control and Prevention (2020) United States COVID-19 cases and deaths by state. https://www.cdc.gov/ coronavirus/2019-ncov/cases-updates/cases-in-us.html. Accessed April 2020

Cranfield JAL (2020) Framing consumer food demand responses in a viral pandemic. Canadian J Agr Econ 68(2):151-156. https://doi. org/10.1111/cjag.12246

Dean WR, Sharkey JR (2011) Rural and urban differences in the associations between characteristics of the community food environment and fruit and vegetable intake. J Nutrition Educ \& Behav 43(6):426433. https://doi.org/10.1016/j.jneb.2010.07.001

Du S, Mroz TA, Zhai F, Popkin BM (2004) Rapid income growth adversely affects diet quality in China: particularly for the poor! Soc Sci Med 59(7):1505-1515. https://doi.org/10.1016/j.socscimed. 2004.01.021

Gracia A, de Magistris T (2008) The demand for organic foods in the south of Italy: a discrete choice model. Food Policy 33:386-396. https://doi.org/10.1016/jfoodpol.2007.12.002

Grashuis J, Skevas T, Segovia MS (2020) Grocery shopping preferences during the COVID-19 pandemic. Sustainability 12(13):5369. https://doi.org/10.3390/su12135369

James P, Arcaya MC, Parker DM, Tucker-Seeley RD, Subramanian SV (2014) Do minority and poor neighborhoods have higher access to fast-food restaurants in the United States? Health \& Place 29:10-17. https://doi.org/10.1016/j.healthplace.2014.04.011

Johns Hopkins University (2020) COVID-19 dashboard by the Center for Systems Science and Engineering (CSSE) at John Hopkins 
University (JHU). https://gisanddata.maps.arcgis.com/apps/ opsdashboard/index.html\#/bda7594740fd40299423467b48e9ecf6. Accessed April 2020

Kim J, Lee JC (2020) Effect of COVID-19 on preference for private dining facilities in restaurants. J Hosp Tour Manag 45:67-70. https://doi.org/10.1016/j.jhtm.2020.07.008

Kim D, Leigh JP (2011) Are meals at full-service and fast-food restaurants "normal" or "inferior"? Pop Health Mgmt 14(6):307-315. https://doi.org/10.1089/pop.2010.0071

Ko LK, Enzler C, Perry CK, Rodriguez E, Marsical N, Linde S, Dugga C (2018) Food availability and food access in rural agricultural communities: use of mixed methods. BMC Public Health 18:634. https://doi.org/10.1186/s12889-018-5547-x

Laguna L, Fiszman S, Puerta P, Chaya C, Tárrega A (2020) The impact of COVID-19 lockdown on food priorities: results from a preliminary study using social media and an online survey with Spanish consumers. Food Qual Prefer 86:1-9. https://doi.org/10.1016/j. foodqual.2020.104028

National Restaurant Association (2019) 2019 restaurant industry factbook. https://www.restaurant.org/Downloads/PDFs/Research/ SOI/restaurant_industry fact_sheet_2019.pdf. Accessed 5 April 2020

Placekey Community (2020) Placekey community. https://www. placekey.io/. Accessed 12 Aug 2020

Robertson SK (2020) Could social distancing create a long-term shift for the grocery industry? The Globe and Mail. https://www. theglobeandmail.com/business/article-could-social-distancingcreate-a-long-term-shift-for-the-grocery/. Accessed 5 April 2020

SafeGraph (2020) The source of truth for POI data \& business listings. https://www.safegraph.com/. Accessed 7 April 2020

Setti M, Falasconi L, Segrè A, Cusano I, Vittuari M (2016) Italian consumers' income and food waste behavior. British Food J 118(7): 1731-1746. https://doi.org/10.1108/BFJ-11-2015-0427

Severson K, Yaffe-Bellany D (2020) Independent restaurants brace for the unknown. New York Times, New York. https://www.nytimes. com/2020/03/20/dining/local-restaurants-coronavirus.html. Accessed 20 March 2020

Sharkey JR (2009) Measuring potential access to food stores and foodservice places in rural areas in the U.S. American J of Preventive Med 36(4):151-155. https://doi.org/10.1016/j.amepre.2009.01.004

Silberholz J (2020) Database mapping a restaurant ID and 12-digit FIPS codes. https://drive.google.com/file/d/1loxmeMEHDusMNbBdG7HQO0RkUeeP1Ia/view. Accessed April 2020
Smith TA, Berning JP, Yang X, Colson G, Dorfman JH (2016) The effects of benefit timing and income fungibility on food purchasing decisions among supplemental nutrition assistance program households. Amer J Agr Econ 98(2):564-580. https://doi.org/10.1093/ ajae/aav072

The New York Times (2020) Coronavirus in the U.S.: latest map and case count. https://www.nytimes.com/interactive/2020/us/coronavirusus-cases.html. Accessed 7 April 2020

United States Bureau of Labor Statistics (2020) Occupational employment statistics. https://www.bls.gov/oes/current/area_emp_chart/ area emp chart.html. Accessed 5 April 2020

United States Census Bureau (2019) Small area income and poverty estimates (SAIPE) program. https://www.census.gov/programssurveys/saipe.html. Accessed 5 March 2020

United States Census Bureau (2020) Advanced monthly sales for retail and food services, March 2020. https://www.census.gov/retail/ releases/historical/marts/adv2003.pdf. Accessed 30 March 2020

United States Department of Agriculture, Economic Research Service (2020) Rural-urban continuum codes. https://www.ers.usda.gov/ data-products/rural-urban-continuum-codes. Accessed 30 March 2020

Wang E, An N, Gao Z, Kiprop E, Geng X (2020) Consumer food stockpiling behavior and willingness to pay for food reserves in COVID-19. Food Security 12:739-747. https://doi.org/10.1007/ s12571-020-01092-1

Weinberg Z (2000) No place to shop: food access lacking in the inner city. Race, Poverty Environ 7(2):22-24 http://www.jstor.org/stable/ 41554277

World Health Organization (2020) WHO director-general's remarks at the media briefing on 2019-nCoV on 11 February 2020. https:// www.who.int/dg/speeches/detail/who-director-general-s-remarksat-the-media-briefing-on-2019-ncov-on-11-february-2020. Accessed April 2020

Zeng Q, Zeng Y (2018) Eating out and getting fat? A comparative study between urban and rural China. Appetite 120:409-415. https://doi. org/10.1016/j.appet.2017.09.027

Publisher's note Springer Nature remains neutral with regard to jurisdictional claims in published maps and institutional affiliations. 